\title{
PEMANFAATAN RFID (RADIO FREQUENCY IDENTIFICATION) SEBAGAI ALTERNATIF ABSENSI SISWA (STUDI KASUS : SMK AR-RAHMAH SUKABUMI, JAWA BARAT)
}

\author{
Febry Eka Purwiantono'), Muhammad Sofwan Romli ${ }^{2)}$ Addin Aditya ${ }^{3)}$ \\ ${ }^{1}$ Manajemen Informatika, STIKI Malang \\ ${ }^{2}$ Komputerisasi Akuntansi, AMIK Citra Buana Indonesia \\ ${ }^{3}$ Sistem Informasi, STIKI Malang \\ 1,3) Jl Raya Tidar No 100, Kota Malang 65146 \\ ${ }^{2}$ Jl. KH. Ahmad Sanusi / Cipalanggede No 24 / 52 Kota Sukabumi, Indonesia \\ Email: ${ }^{1}$ febry@stiki.ac.id, ${ }^{2}$ muhammadsofwanromli@yahoo.com, ${ }^{3}$ addin@stiki.ac.id
}

\begin{abstract}
Abstrak
Sampai saat ini sistem absensi di hampir seluruh institusi Pendidikan masih menggunakan kertas dan tinta. Hal ini menyebabkan sering munculnya celah bagi para siswa untuk tidak absen dan membolos saat kegiatan belajar mengajar. Tujuan dari penelitian ini adalah untuk membuat sebuah sistem informasi absensi dengan menggunakan teknologi nirsentuh yang dalam hal ini adalah RFID (Radio Frequency Identification). Teknologi ini nantinya akan menggantikan peran kertas dan tinta untuk merekam kehadiran siswa dan guru agar mempermudah operator sekolah dalam pelaporan absensi kepada pihak-pihak yang berkepentingan. Hasil menunjukkan bahwa sistem sudah mampu untuk mengendalikan proses absensi yang terjadi pada SMK Ar-Rahmah dan sudah dapat dilaporkan dengan baik. Namun perlu adanya kajian lebih lanjut mengenai peningkatan peran teknologi nirsentuh dalam menangani absensi siswa agar sistem dapat berjalan lebih baik dengan mengkolaborasikan peran manusia dengan peran teknologi informasi itu sendiri.
\end{abstract}

Kata Kunci: Absensi Siswa, RFID, Sistem Informasi, SMK Ar-Rahmah Sukabumi, Teknologi Nirsentuh

\section{Pendahuluan}

Perkembangan teknologi yang pesat di era global memaksa masyarakat untuk selalu hidup berdampingan dengan teknologi. Sampai saat ini pelaksanaan kegiatan belajar mengajar untuk lingkungan Pendidikan sekolah menengah di Indonesia masih menggunakan sistem absensi konfensional sebagai media perekaman kehadiran siswa di sekolah. Secara garis besar, absensi adalah suatu pendataan kehadiran, bagian dari pelaporan aktifitas suatu institusi yang berisi data kehadiran yang diatur sedemikian rupa supaya mudah dicari apabila sewaktu-waktu diperlukan oleh pihak yang berkepentingan [1].

Tujuan utama dari penelitian ini adalah membangun sebuah sistem informasi untuk merekam dan merekap data kehadiran atau absensi siswa di SMK Ar-Rahmah Sukabumi dengan memanfaatkan Radio Frequency Identification (RFID). Untuk saat ini SMK Ar-Rahmah Sukabumi masih menggunakan absensi secara manual baik untuk siswa maupun guru.

Guru akan merekap kehadiran siswa-siswi sebelum pelajaran dimulai. Tentunya hal ini dirasa kurang efektif dan mempersulit guru maupun ketua kelas, karena sistem absensi secara manual membutuhkan waktu rekapitulasi yang cukup lama [2]. Selain kegiatan belajar mengajar, sistem absensi manual juga diberlakukan untuk kegiatan ekstrakulikuler yang ada di SMK Ar-Rahmah Sukabumi. Bahkan untuk absensi guru juga masih menggunakan sistem absensi manual yaitu menulis di buku absensi guru. Seperti yang sudah diketahui sebelumnya, sistem absensi secara manual ini memang sangat mudah dicurangi maupun dimanipulasi.

Oleh sebab itu peneliti mengusulkan teknik absensi baru yaitu sistem absensi siswa menggunakan RFID berbasis web. Teknologi ini memungkinkan pelacakan dan identifikasi objek dan makhluk hidup menggunakan radio. Berbeda dengan teknologi barcode, RFID tidak menggunakan kontak atau garis-sight [3]. Selain itu, teknologi barcode juga memiliki kelemahan lain yaitu rawan digunakan untuk titip kehadiran dan jarak deteksi barcode terhadap alat pendeteksi barcode tidak boleh lebih dari $2 \mathrm{~cm}$ agar akurasinya maksimal [4]. Sedangkan teknologi RFID mampu bekerja secara optimal dengan jarak maksimal $10 \mathrm{~cm}$ [5] dan masih bisa bekerja meskipun antara reader dan tag terhalang dengan maksimal ketebalan penghalang $4 \mathrm{~cm}$ [6].

Tentunya dengan kelebihan yang ditawarkan, teknologi RFID dapat digunakan untuk mendukung peran sistem informasi akademik yang ada serta, menghemat kertas yang digunakan untuk absensi sekaligus meringankan pekerjaan guru. Dengan demikian diharapakan sistem ini dapat meningkatkan kedisiplinan siswa maupun guru dalam mengikuti kegiatan belajar mengajar maupun ekstrakulikuler di di SMK Ar-Rahmah Sukabumi. Sedangkan bagi masyarakat, penelitian ini dapat memberikan kontribusi pengembangan teknologi RFID serta menambah referensi dalam penelitian bidang teknologi informasi. 


\section{Tinjauan Pustaka}

\subsection{Radio Frequency Identification (RFID)}

Karena adanya tekanan tentang privasi individu, maka wajar jika teknologi RFID berkembang dengan pesat. Teknologi RFID adalah sebuah sistem otomatis menangkap data nirkabel, yang terdiri dari dua bagian: tag (responder) dan pembaca [7]. tag adalah sebuah chip silikon yang berisi informasi, biasanya angka pengenal yang unik yang dapat dibaca oleh RFID reader melalui gelombang radio. Tergantung pada frekuensi radio dan sumber daya, pembaca dapat mengambil gelombang radio pada kisaran antara tiga dan tiga puluh kaki dan membaca informasi yang tersimpan pada chip [8].

Pada Gambar 1 menunjukkan began komponen utama dari RFID, yakni tag, reader, antenna dan interface. tag atau transponder bisa aktif, pasif atau semiaktif. Komponen ini merespon sinyal dari interrogator (reader / writer / antenna) yang mana sinyal diteruskan menuju komputer. Bentuk dari sebuah tag bisa bervariasi. Komponen ini bisa terbuat dari IC (chip) dan sebuah antenna, tergantung dari aplikasinya, komponen ini dapat dibenamkan kaca, epoxy, plastik, label atau sebuah kartu.
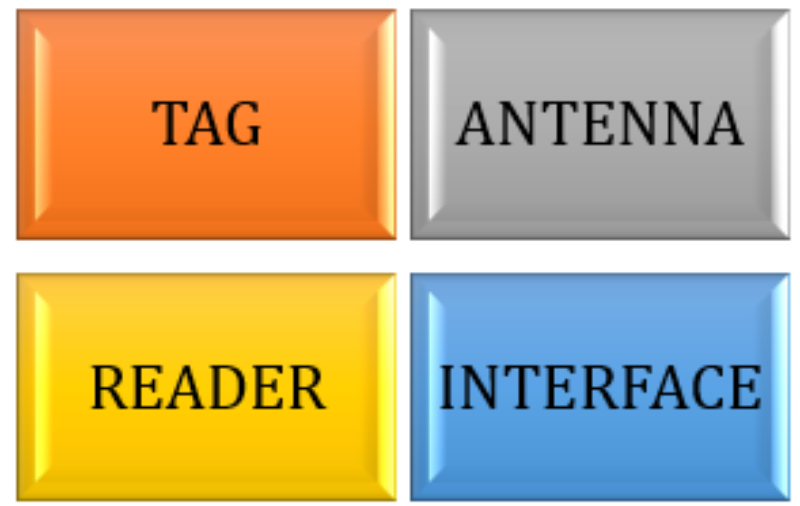

Gambar 1. Komponen Utama RFID

\subsection{Sistem Absensi Nirsentuh}

Sistem absensi nirsentuh dapat menjadi alternatif pilihan untuk memudahkan proses pendataan siswa apabila penggunanya banyak [9]. Selain itu, waktu tunggu pengguna dalam menggunakan sistem juga tergolong singkat. Mesin absensi generic adalah sebuah mesin untuk mendata pengguna secara elektronik dengan menggunakan scan kartu.

Umumnya mesin ini digunakan untuk kebutuhan absensi, selain itu juga dapat dimanfaatkan untuk identifikasi dan otorisasi user. Dalam implementasinya, sistem informasi nirsentuh masih memiliki kekurangan. Semisal kemungkinan kartu identitas yang mudah hilang ataupun dapat dipinjam oleh user lain. Namun kelebihannya sistem ini akan dapat mendata banyak pengguna dengan waktu yang singkat.

\section{Hasil dan Pembahasan}

Absensi manual memiliki berbagai kekurangan seperti adanya kecurangan, ketidakefektifan, membutuhkan banyak kertas dan tinta, membutuhkan ruangan penyimpanan dan lain sebagainya. Kekurangan tersebut dapat difasilitasi dengan memanfaatkan teknologi semi-konduktor yang perkembangannya semakin pesat [10]. Untuk implementasi, sistem ini dibagi dengan beberapa menu utama. Masing-masing dari menu akan diberikan input dan actor yang berbeda sehingga akan mempengaruhi proses dan luaran yang berbeda pula.

Pada Gambar 2 menunjukkan tampilan antarmuka dari halaman utama aplikasi. Pada halaman utama ini digunakan bagi siswa dan guru untuk menempelkan kartu kepada alat RFID sehingga nanti akan diverifikasi oleh sistem dan akan menampilakan status kehadiran dari user.

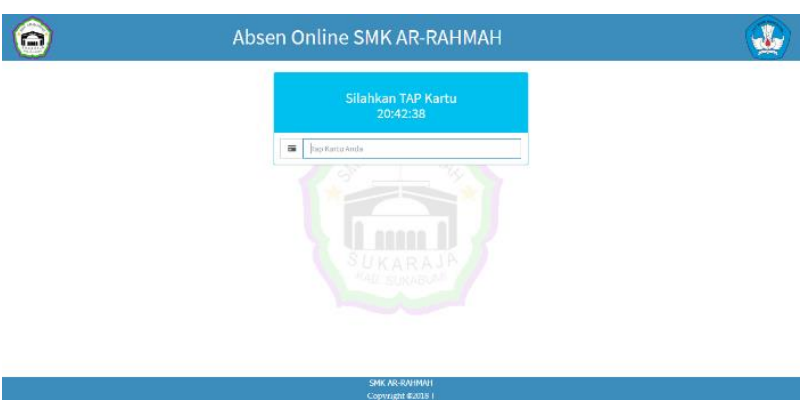

Gambar 2. Tampilan Antarmuka Halaman Utama

Untuk detail dari halaman utama dapat dilihat pada Tabel 1 di bawah ini :

Tabel 1. Deskripsi Halaman Utama

\begin{tabular}{lll}
\hline \multicolumn{1}{c}{ Objek } & \multicolumn{1}{c}{ Penggunaan } & \multicolumn{1}{c}{ Keterangan } \\
\hline Tap Kartu & $\begin{array}{l}\text { Tempelkan kartu } \\
\text { RFID atau ketik } \\
\text { nomor kartu }\end{array}$ & $\begin{array}{l}\text { Memverifikasi } \\
\text { kartu RFID yang } \\
\text { di tempelkan }\end{array}$ \\
\hline Foto avatar & Hanya lihat & $\begin{array}{l}\text { Menampilkan } \\
\text { foto sesuai } \\
\text { dengan kartu } \\
\text { RFID yang di tap }\end{array}$ \\
\hline Nama & Hanya lihat & $\begin{array}{l}\text { Menampilkan } \\
\text { nama pemilik } \\
\text { kartu }\end{array}$ \\
\hline Status & Hanya Lihat & $\begin{array}{l}\text { Menampilkan } \\
\text { Status pembacaan } \\
\text { kartu }\end{array}$ \\
\hline & & $\begin{array}{l}\text { Menampilkan jam } \\
\text { masuk/keluar } \\
\text { Kenampilkan } \\
\text { informasi }\end{array}$ \\
& & ketersedian \\
& & jadwal \\
\hline
\end{tabular}


Selanjutnya terdapat halaman login seperti yang terlihat pada Gambar 3. Halaman login ini digunakan oleh operator sekolah untuk masuk sistem.

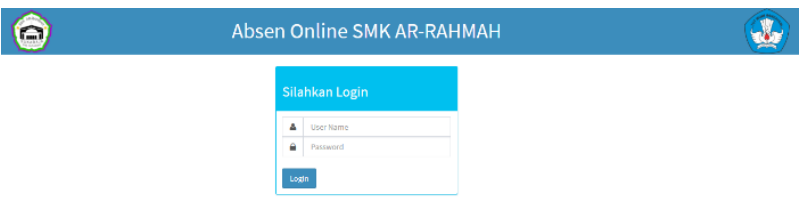

Gambar 3. Halaman Login Aplikasi

Perlu diketahui bahwa hanya operator yang dapat masuk ke dalam sistem. Tampilan halaman login sengaja dibuat sesederhana agar operator tidak kesusahan dalam memasukkan username dan password. Sedangkan pada Tabel 2 merupakan deskripsi halaman login.

Tabel 2. Deskripsi Halaman Login

\begin{tabular}{rll}
\hline \multicolumn{1}{c}{ Objek } & \multicolumn{1}{c}{ Penggunaan } & \multicolumn{1}{c}{ Keterangan } \\
\hline & Mengisi & Hak akses \\
Otentikasi & username dan & penggunaan \\
pengguna & password & untuk akun yang \\
& $\begin{array}{l}\text { terdaftar, lalu } \\
\text { tekan "Login" }\end{array}$ & valid \\
\hline
\end{tabular}

Setelah masuk sebagai operator, maka akan muncul menu utama aplikasi (hak akses sebagai admin). Sebagian besar fungsi utama dari menu utama adalah sebagai navigasi untuk menuju fitur-fitur yang lain. Pada Tabel 3 akan dijelaskan mengenai deskripsi dari halaman menu utama.

Tabel 3. Deskripsi Halaman Menu Utama

\begin{tabular}{|c|c|c|}
\hline Objek & Penggunaan & Keterangan \\
\hline $\begin{array}{l}\text { Link Master } \\
\text { Data }\end{array}$ & $\begin{array}{l}\text { Tekan tombol } \\
\text { "Master Data", }\end{array}$ & $\begin{array}{l}\text { Menampilkan } \\
\text { sub menu } \\
\text { master data }\end{array}$ \\
\hline $\begin{array}{l}\text { Link Tahun } \\
\text { Pelajaran }\end{array}$ & $\begin{array}{l}\text { Tekan tombol } \\
\text { "Tahun } \\
\text { Pelajaran" }\end{array}$ & $\begin{array}{l}\text { Mengelola } \\
\text { tahun pelajaran }\end{array}$ \\
\hline Link Guru & $\begin{array}{l}\text { Tekan Tombol } \\
\text { "Guru" }\end{array}$ & $\begin{array}{l}\text { Mengelola data } \\
\text { guru }\end{array}$ \\
\hline Link Siswa & $\begin{array}{l}\text { Tekan tombol } \\
\text { "Siswa" }\end{array}$ & $\begin{array}{l}\text { Mengelola data } \\
\text { siswa }\end{array}$ \\
\hline $\begin{array}{l}\text { Link Kelas } \\
\text { Siswa }\end{array}$ & $\begin{array}{l}\text { tekan tombol } \\
\text { "Kelas Siswa" }\end{array}$ & $\begin{array}{l}\text { Mengelola data } \\
\text { siswa per kelas } \\
\text { per tahun } \\
\text { pelajaran }\end{array}$ \\
\hline $\begin{array}{l}\text { Link } \\
\text { Ekstrakurikuler }\end{array}$ & $\begin{array}{l}\text { Tekan tombol } \\
\text { "Ekstrakurikuler" }\end{array}$ & $\begin{array}{l}\text { Menampilkan } \\
\text { sub menu } \\
\text { Ekstrakurikuler }\end{array}$ \\
\hline Link Daftar & $\begin{array}{l}\text { Tekan tombol } \\
\text { "Daftar" }\end{array}$ & $\begin{array}{l}\text { Mengelola } \\
\text { daftar }\end{array}$ \\
\hline
\end{tabular}

\begin{tabular}{|c|c|c|}
\hline & & Ekstrakurikuler \\
\hline Link Anggota & $\begin{array}{l}\text { Tekan tombol } \\
\text { "Anggota" }\end{array}$ & $\begin{array}{l}\text { Mengelola } \\
\text { siswa anggota } \\
\text { ekstrakurikuler }\end{array}$ \\
\hline Link Absen & $\begin{array}{l}\text { Tekan tombol } \\
\text { "Absen" }\end{array}$ & $\begin{array}{l}\text { Menampilkan } \\
\text { sub menu } \\
\text { Absen }\end{array}$ \\
\hline Link Kelas & $\begin{array}{l}\text { Tekan tombol } \\
\text { "Absen->Kelas" }\end{array}$ & $\begin{array}{l}\text { Mengelola } \\
\text { Absen per kelas }\end{array}$ \\
\hline $\begin{array}{l}\text { Link } \\
\text { Ekstrakurikuler }\end{array}$ & $\begin{array}{l}\text { Tekan tombol } \\
\text { "Absen- } \\
\text { >Ekstrakurikuler" }\end{array}$ & $\begin{array}{l}\text { Mengelola } \\
\text { Absen } \\
\text { ekstrakurikuler }\end{array}$ \\
\hline Link guru & $\begin{array}{l}\text { Tekan tombol } \\
\text { "Absen->Guru" }\end{array}$ & $\begin{array}{l}\text { Mengelola } \\
\text { Absen Guru }\end{array}$ \\
\hline Link Rekap & $\begin{array}{l}\text { Tekan tombol } \\
\text { "Rekap" }\end{array}$ & $\begin{array}{l}\text { Menampilkan } \\
\text { submenu } \\
\text { Rekap }\end{array}$ \\
\hline Link Kelas & $\begin{array}{l}\text { Tekan tombol } \\
\text { "Rekap->Kelas" }\end{array}$ & $\begin{array}{l}\text { Menampilkan } \\
\text { rekap absen per } \\
\text { kelas }\end{array}$ \\
\hline $\begin{array}{l}\text { Link } \\
\text { Ekstrakurikuler }\end{array}$ & $\begin{array}{l}\text { Tekan tombol } \\
\text { "Rekap- } \\
\text { >Ekstrakurikuler" }\end{array}$ & $\begin{array}{l}\text { Menampilkan } \\
\text { rekap absen } \\
\text { ekstrakurikuler }\end{array}$ \\
\hline Link Guru & $\begin{array}{l}\text { Tekan tombol } \\
\text { "Rekap->Guru" }\end{array}$ & $\begin{array}{l}\text { Menampilkan } \\
\text { rekap absen } \\
\text { guru }\end{array}$ \\
\hline $\begin{array}{l}\text { Link } \\
\text { Pengaturan } \\
\text { Jadwal }\end{array}$ & $\begin{array}{l}\text { Tekan tombol } \\
\text { "Pengaturan } \\
\text { Jadwal" }\end{array}$ & $\begin{array}{l}\text { Menampilkan } \\
\text { sub menu } \\
\text { pengaturan } \\
\text { jadwal }\end{array}$ \\
\hline $\begin{array}{l}\text { Link Jadwal } \\
\text { Kelas }\end{array}$ & $\begin{array}{l}\text { Tekan tombol } \\
\text { "Pengaturan } \\
\text { Jadwal-> Jadwal } \\
\text { Kelas" }\end{array}$ & $\begin{array}{l}\text { Mengelola } \\
\text { jadwal masuk } \\
\text { dan pulang } \\
\text { siswa per kelas }\end{array}$ \\
\hline $\begin{array}{l}\text { Link Jadwal } \\
\text { Guru }\end{array}$ & $\begin{array}{l}\text { Tekan tombol } \\
\text { "Pengaturan } \\
\text { Jadwal-> Jadwal } \\
\text { Guru" }\end{array}$ & $\begin{array}{l}\text { Mengelola } \\
\text { jadwal } \\
\text { mengajar guru }\end{array}$ \\
\hline
\end{tabular}

Pada Gambar 4 dapat dilihat bentuk dari halaman menu utama dengan hak akses sebagai operator sekolah.

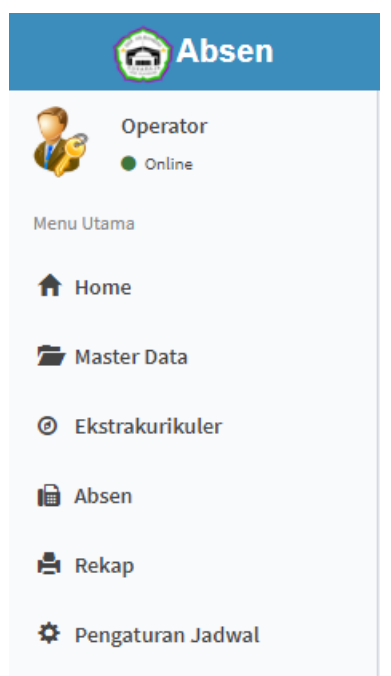

Gambar 4. Tampilan Menu Utama 
Dari sistem ini terdapat salah satu fitur utama yaitu fitur absensi siswa seperti yang terlihat pada Gambar 5. Halaman ini digunakan oleh operator untuk mengelola data absen siswa. Halaman ini memiliki fitur untuk mencetak absen siswa berdasarkan tanggal tertentu, mengunduh data absen siswa setiap kelas berdasarkan tanggalnya ke dalam format tertentu.

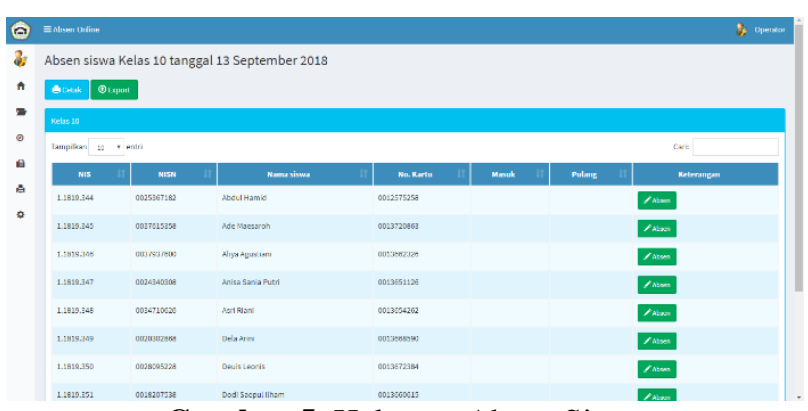

Gambar 5. Halaman Absen Siswa

Berdasarkan fungsi dan tujuan dari halaman absensi siswa, maka dapat dipetakan deskripsi dari halaman absensi siswa berdasarkan objek dan tujuan dari masingmasing fitur yang tertuang pada Tabel 4 di bawah ini.

Tabel 4. Deskripsi Halaman Absen Siswa

\begin{tabular}{|c|c|c|}
\hline Objek & Penggunaan & Keterangan \\
\hline Cetak & $\begin{array}{l}\text { Tekan tombol } \\
\text { "Cetak" }\end{array}$ & $\begin{array}{l}\text { Mencetak absen } \\
\text { siswa per kelas per } \\
\text { tanggal }\end{array}$ \\
\hline Export & $\begin{array}{l}\text { Tekan tombol } \\
\text { "Export" }\end{array}$ & $\begin{array}{l}\text { Mengunduh data } \\
\text { absen siswa per } \\
\text { kelas pertanggal } \\
\text { kedalam format } \\
\text { spreadsheet }\end{array}$ \\
\hline Absen & $\begin{array}{l}\text { Tekan tombol } \\
\text { "Absen" }\end{array}$ & $\begin{array}{l}\text { Menampilkan pop- } \\
\text { up untuk mengisi } \\
\text { kehadiran siswa } \\
\text { jika siswa tersebut } \\
\text { tidak men-TAP } \\
\text { kartu. Tombol ini } \\
\text { tidak akan } \\
\text { muncul jika siswa } \\
\text { telah men-TAP } \\
\text { kartu RFID }\end{array}$ \\
\hline
\end{tabular}

Selain digunakan untuk absensi siswa sehari-hari, sistem ini juga dapat digunakan untuk absensi ekstrakurikuler. Menu ini digunakan untuk merekam kehadiran siswa dalam pelaksanaan ekstrakurikuler di sekolah. Seperti yang diketahui ekstrakurikuler juga menjadi penilaian siswa. Menu ini digunakan oleh operator sekolah. Tabel 5 akan menunjukkan deskripsi lengkap dari kebutuhan menu absensi ekstrakurikuler siswa.
Tabel 5. Deskripsi Menu Pengelolaan Absensi Ekstrakurikuler Siswa

\begin{tabular}{|c|c|c|}
\hline Objek & Penggunaan & Keterangan \\
\hline Cetak & $\begin{array}{l}\text { Tekan tombol } \\
\text { "Cetak" }\end{array}$ & $\begin{array}{l}\text { Mencetak absen } \\
\text { Kegiatan } \\
\text { Ekstrakurikuler per } \\
\text { tanggal }\end{array}$ \\
\hline Export & $\begin{array}{l}\text { Tekan tombol } \\
\text { "Export" }\end{array}$ & $\begin{array}{l}\text { Mengunduh data } \\
\text { Absen Kegiatan } \\
\text { Ekstrakurikuler } \\
\text { pertanggal kedalam } \\
\text { format spreadsheet }\end{array}$ \\
\hline Absen & $\begin{array}{l}\text { Tekan tombol } \\
\text { "Absen" }\end{array}$ & $\begin{array}{l}\text { Menampilkan pop- } \\
\text { up untuk mengisi } \\
\text { kehadiran Kegiatan } \\
\text { Ekstrakurikuler jika } \\
\text { siswa tersebut tidak } \\
\text { men-TAP kartu. } \\
\text { Tombol ini tidak } \\
\text { akan muncul jika } \\
\text { siswa telah men- } \\
\text { TAP kartu RFID }\end{array}$ \\
\hline
\end{tabular}

Sedangkan pada Gambar 6 merupakan tampilan antarmuka dari menu absensi ekstrakurikuler. Selain digunakan untuk memberikan fasilitas rekap data kehadiran siswa di ekstrakurikuler, menu ini juga bisa memberikan fungsi pelaporan serta pencarian data.

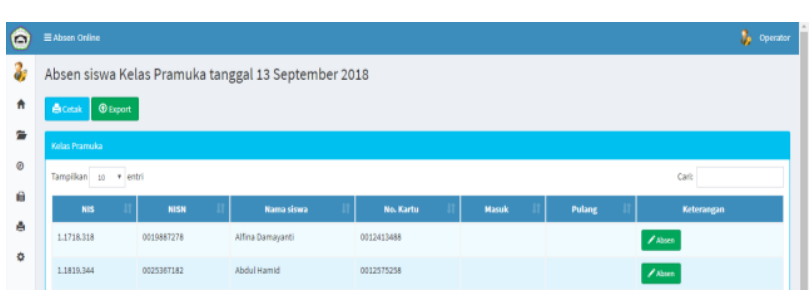

Gambar 6. Tampilan Antarmuka Rekap Kehadiran Ekstrakurikuler Siswa

Selain siswa, aplikasi ini juga mampu memfasilitasi absensi untuk guru. Fungsi dari menu ini tidak terlalu berbeda dengan absensi siswa. Tabel 6 menunjukan dokumentasi kebutuhan menu absensi guru.

Tabel 6. Dokumen Kebutuhan Menu Absensi Guru

\begin{tabular}{|c|c|c|}
\hline Objek & Penggunaan & Keterangan \\
\hline Cetak & $\begin{array}{l}\text { Tekan tombol } \\
\text { "Cetak" }\end{array}$ & $\begin{array}{l}\text { Mencetak absen } \\
\text { Guru per kelas per } \\
\text { tanggal }\end{array}$ \\
\hline Export & $\begin{array}{l}\text { Tekan tombol } \\
\text { "Export" }\end{array}$ & $\begin{array}{l}\text { Mengunduh data } \\
\text { absen Guru per } \\
\text { kelas pertanggal } \\
\text { kedalam format } \\
\text { spreadsheet }\end{array}$ \\
\hline
\end{tabular}




\begin{tabular}{|c|c|c|}
\hline Absen & $\begin{array}{l}\text { Tekan tombol } \\
\text { "Absen" }\end{array}$ & $\begin{array}{l}\text { Menampilkan } \\
\text { pop-up untuk } \\
\text { mengisi kehadiran } \\
\text { Guru jika Guru } \\
\text { tersebut tidak } \\
\text { men-TAP kartu. } \\
\text { Tombol ini tidak } \\
\text { akan muncul jika } \\
\text { Guru telah men- } \\
\text { TAP kartu RFID }\end{array}$ \\
\hline
\end{tabular}

Gambar 7 menunjukkan tampilan antar muka dari menu absensi guru. Menu ini tidak jauh berbeda dengan menu absensi siswa. Menu ini juga memiliki fungsi cetak dan eksport dengan format tertentu guna memudahkan pelaporan pihak manajemen.

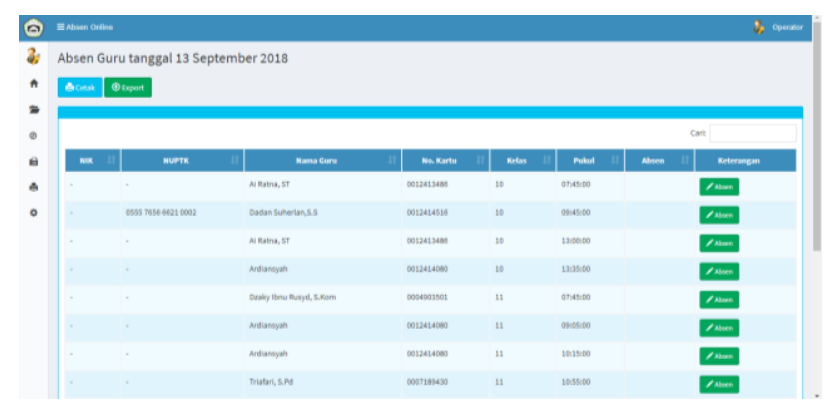

Gambar 7. Tampilan Antarmuka Menu Absensi Guru

Untuk melengkapi pelaporan absensi siswa, dibutuhkan sebuah menu khusus untuk memantau kehadiran siswa. Menu ini digunakan untuk melihat, mencetak dan mengunduh data rekap kehadiran siswa tiap kelas dan dapat dicetak dalam periode bulanan. Menu tersebut dapat dilihat pada Gambar 8 (tampilan antarmuka dari menu rekap kehadiran siswa).

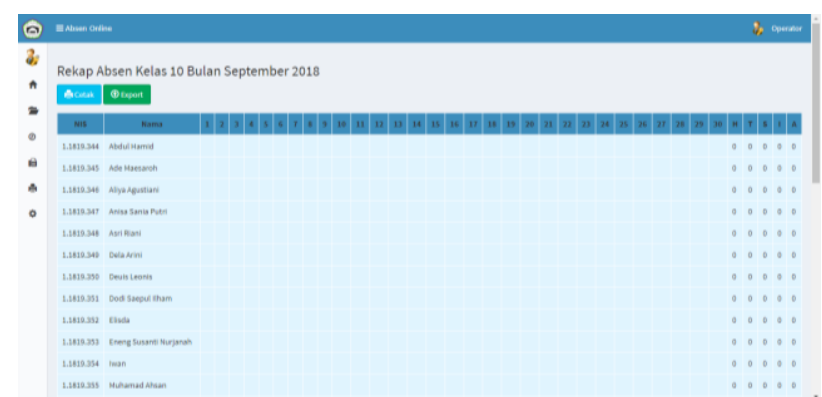

Gambar 8. Tampilan Antarmuka Rekap Data Kehadiran Siswa

Sedangkan untuk Tabel 7 menunjukkan dokumentasi kebutuhan menu rekap kehadiran siswa.

Tabel 7. Dokumentasi Kebutuhan Menu Rekap Kehadiran Siswa

\begin{tabular}{rll}
\hline Objek & Penggunaan & \multicolumn{1}{c}{ Keterangan } \\
\hline & & Mencetak \\
Cetak & Tekan tombol & rekapitulasi absen \\
& "Cetak" & $\begin{array}{l}\text { Siswa per kelas } \\
\text { dalam satu bulan }\end{array}$ \\
\hline
\end{tabular}

\begin{tabular}{lll}
\hline & & $\begin{array}{l}\text { Mengunduh } \\
\text { rekapitulasi absen }\end{array}$ \\
Export & Tekan tombol & Siswa per kelas \\
& "Export" & dalam satu bulan \\
& kedalam format \\
& spreadsheet \\
\hline
\end{tabular}

\section{Kesimpulan}

Berdasarkan dari hasil dan pembahasan sebelumnya, dapat diambil kesimpulan bahwa sistem ini sudah mampu untuk mengelola data absensi siswa maupun guru hingga pelaporan kepada pihak-pihak yang berkepentingan. Sehingga guru tidak perlu lagi melakukan absensi kepada siswanya secara manual, begitupula dengan guru yang tidak perlu lagi menulis tanda tangan di buku absensi sebagai syarat kehadiran.

Namun sejatinya sistem tidak dibuat untuk menggantikan peran manusia. Perlu adanya sebuah kajian yang lebih mendalam mengenai peran manusia dalam pengelolaan sistem absensi dengan memanfaatkan teknologi informasi agar pengelolaan absensi siswa dan guru tetap berjalan efektif dan efisiensi dengan mengkolaborasikan tenaga manusia dan teknologi informasi.

\section{Daftar Pustaka}

[1] M. L. Harumy, T.H.F., Julham Sitorus, "Sistem Informasi Absensi Pada Pt . Cospar Sentosa Jaya Menggunakan Bahasa Pemprograman Java," J. Tek. Informartika, vol. 5, no. 1, pp. 63-70, 2018.

[2] M. Yusuf, R. V. H. Ginardi, and A. S. Ahmadiyah,

"Rancang Bangun Aplikasi Absensi Perkuliahan Mahasiswa dengan Pengenalan Wajah," J. Tek. ITS, 2019.

[3] K. G. Akintola and O. K. Boyinbode, "The place of emerging RFID technology in national security and development," Int. J. Smart Home, 2011.

[4] A. Fadlil, K. Firdausy, and F. Hermawan, "PENGEMBANGAN SISTEM BASIS DATA PRESENSI PERKULIAHAN DENGAN KARTU MAHASISWA BER-BARCODE," TELKOMNIKA (Telecommunication Comput. Electron. Control., 2015.

[5] J. T. Elektro, F. Teknik, U. J. Unej, and J. Kalimantan, "Rancang Bangun Perangkat Rekam Medik Berbasis Teknologi RFID ( Hospital Medical Record Tools Based RFID Technology )," no. 2, pp. 104-111, 2017.

[6] O. Y. Senna, H. Supriyono, and T. Retail, "Sistem transaksi barang retail menggunakan rfid," vol. 16, no. 02, pp. 13-17, 2015.

[7] F. M. Dewanto, B. A. Herlambang, and Aris Tri Jaka Harjanta, "Pengembangan Sistem Informasi Absensi Berbasis Radio Frequency Identification (RFID) Terintegrasi dengan Sistem Informasi Akademik," J. Inform. J. Pengemb. IT, 2017. 
[8] T. Kurniawan, P. Tarigan, and F. Akbar, "ANALISIS YURIDIS PERMOHONAN IZIN PENYELENGGARAAN RADIO PADA FREKUENSI 99,5 MEGAHERTZ (PERKARA TATA USAHA NEGARA NOMOR 86/G/2010/PTUN-MEDAN)," USU Law J., vol. 3, no. 2, pp. 138-147, 2015.

[9] V. O. Panggabean and F. Pandi, "Sistem Absensi Berbasis Radio Frequency Identification ( RFID )
Pada Mikroskil,” JSM STMIK Mikroskil, vol. 14, no. 2, pp. 129-138, 2013.

[10] H. Y. Fauziah, A. I. Sukowati, and I. Purwanto, "Rancang Bangun Sistem Absensi Mahasiswa Sekolah Tinggi Teknik Cendekia (STTC) Berbasis Radio Frequency Identification (RFID) menggunakan Arduino UNO R3," Semnastek Umj, 2017. 